\title{
Air pollution and neonatal deaths in São Paulo, Brazil
}

\section{C.A. Lin ${ }^{1}$, L.A.A. Pereira ${ }^{1}$, D.C. Nishioka ${ }^{1}$, G.M.S. Conceição ${ }^{1}$, A.L.F. Braga ${ }^{1,2}$ and P.H.N. Saldiva ${ }^{1}$}

\author{
${ }^{1}$ Laboratório de Poluição Atmosférica Experimental, Departamento de Patologia \\ (LIM 05), Faculdade de Medicina, Universidade de São Paulo, São Paulo, SP, Brasil \\ ${ }^{2}$ Programa de Pediatria Ambiental, Departamento de Pediatria, \\ Faculdade de Medicina, Universidade de Santo Amaro, São Paulo, SP, Brasil
}

\author{
Correspondence \\ C.A. Lin \\ Laboratório de Poluição Atmosférica \\ Experimental \\ Departamento de Patologia, FM, USP \\ Av. Dr. Arnaldo, 455 \\ 01246-903 São Paulo, SP \\ Brasil \\ E-mail: calin@uol.com.br
}

Presented at the 1st Symposium on Advances in Medical Research, Institute of Medical Investigation Laboratories, HC-FMUSP, São Paulo, SP, Brazil, March 21-22, 2003.

Research supported by FAPESP, CNPq, PRONEX and LIM-HCFMUSP.

Received June 12, 2003

Accepted March 4, 2004

\begin{abstract}
Air pollution has been associated with health effects on different age groups. The present study was designed to assess the impact of daily changes in air pollutants $\left(\mathrm{NO}_{2}, \mathrm{SO}_{2}, \mathrm{CO}, \mathrm{O}_{3}\right.$, and particle matter $\left(\mathrm{PM}_{10}\right)$ ) on total number of daily neonatal deaths (those that occur between the first and the 28th days of life) in São Paulo, from January 1998 to December 2000, since adverse outcomes such as neonatal deaths associated with air pollution in Brazil have not been evaluated before. Generalized additive Poisson regression models were used and nonparametric smooth functions (loess) were adopted to control longterm trend, temperature, humidity, and short-term trends. A linear term was used for holidays. The association between air pollutants and neonatal deaths showed a short time lag. Interquartile range increases in $\mathrm{PM}_{10}\left(23.3 \mu \mathrm{g} / \mathrm{m}^{3}\right)$ and $\mathrm{SO}_{2}\left(9.2 \mu \mathrm{g} / \mathrm{m}^{3}\right)$ were associated with increases of $4 \%(95 \%$ CI, 2-6) and $6 \%$ (95\% CI, 4-8), respectively. Instead of adopting a two-pollutant model we created an index to represent $\mathrm{PM}_{10}$ and $\mathrm{SO}_{2}$ effects. For an interquartile range increase in the index an increase of $6.3 \%(95 \%$ CI, 6.1-6.5) in neonatal deaths was observed. These results agree with previous studies performed by our group showing the deleterious effects of air pollutants during the perinatal period. The method reported here represents an alternative approach to analyze the relationship between highly correlated pollutants and public health problems, reinforcing the idea of the synergic effects of air pollutants in public health.
\end{abstract}

\section{Introduction}

Air pollution has been positively associated with several adverse outcomes in public health for different age groups. Several studies have indicated that aged people as well as the children's populations are more sensitive to both the acute and chronic adverse effects
Key words

- Neonatal mortality

- Infant mortality

- Air pollution 
strong association between air pollution and hospital admissions due to respiratory problems for children and adolescents younger than 13 years. Analyses stratified by age group showed that the strongest effects occur among infants (17).

Using a retrospective cohort study, Woodruff and colleagues (18) demonstrated an association between air pollution, mainly particle matter $\left(\mathrm{PM}_{10}\right)$, and postneonatal mortality in the USA.

Other studies have shown that the effects of air pollutants can start as early as during pregnancy. Ritz and colleagues $(19,20)$ investigated the birth outcomes due to air pollution in California, USA, and found a positive association between air pollution and both birth defects (19) and preterm birth (20). Wang and colleagues (21) and Bobak and Leon (22) reported associations between air pollutants and low birth weight. Also, Pereira and co-workers (23) demonstrated a positive association between intrauterine death and air pollution. This last investigation, a pioneering one in Brazil, is relevant because it clearly shows that an increase in the level of air pollutants is associated with late fetal loss, raising questions about the possible association between air pollution and neonatal outcomes.

The results of these studies have suggested that the younger the subjects the stronger the health effects of air pollution.

In order to test this hypothesis, we carried out a time series study evaluating the daily air pollution exposure and total neonatal mortality in São Paulo between 1998 and 2000 .

\section{Material and Methods}

The Municipal Mortality Information Improvement Program (PROAIM) provided daily counts of total neonatal deaths (up to 28 days after birth) in the city of São Paulo from January 1998 to December 2000.

The São Paulo State Sanitary Agency
(CETESB) provided daily records of $\mathrm{NO}_{2}$, $\mathrm{SO}_{2}, \mathrm{CO}, \mathrm{O}_{3}$, and $\mathrm{PM}_{10}$ concentrations (24). The pollutant levels recorded at each station were averaged and considered to be indicative of the citywide status. Information on daily minimum temperature and relative humidity was provided by the Institute of Astronomy and Geophysics of the University of São Paulo (IAG-USP).

Statistical modeling was done using Poisson regression techniques in generalized additive models, which are widely employed in time-series studies investigating the effects of air pollution on public health (7). Daily number of neonatal deaths was used as the dependent variable in the models and locally weighted running line smoother (loess), a nonparametric function, was used to control for time (long-term trend), temperature, humidity, and days of the week, assuming a nonlinear behavior of these parameters. A linear term was used for holidays. Our basic model was defined as follows:

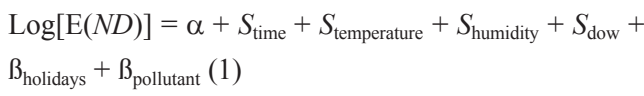

were $N D$ is the daily count of neonatal deaths and $\mathrm{E}(N D)$ is the expected value of that count, $S$ is the nonparametric smooth function and $B$ is the regression coefficient of linear terms. Autoregressive terms were included in the models when the analysis of the autocorrelation plots indicated the necessity of minimizing the autocorrelation of the residuals.

The effect of air pollutants was estimated using the air pollutant levels on the concurrent day and moving averages from two to seven days in single-pollutant models. Copollutant models were adopted for those pollutants that presented a positive and statistically significant association with the outcome in single-pollutant models. The high correlation between primary pollutants and their mixture in outdoor air makes it difficult to accept that adverse effects may be attrib- 
uted to a single pollutant. An index of air pollution was created with the pollutants included in the co-pollutant models, an approach already used in a previous study by our group (23). The index was defined as follows:

Index $=\frac{\frac{\text { pollutant }_{1}}{\mu_{1}}+\frac{\text { pollutant }_{2}}{\mu_{2}}+\ldots+\frac{\text { pollutant }_{p}}{\mu_{p}}}{p}$

where $p$ is the number of pollutants and $\mu$ is the mean value of the pollutant concentration during the study period.

The results are reported as percent increase in neonatal deaths due to interquartile range increases in air pollutant levels. The $95 \%$ confidence intervals were estimated assuming normal distributions of the residuals.

\section{Results}

Descriptive measures (mean, standard error, minimum and maximum values, and the number of days during the study period for which information was available) of the variables under investigation are shown in Table 1. Data were available for all days during the study period and all pollutants showed lower daily mean levels compared to their primary standards.

Table 2 presents the pairwise Pearson correlation coefficients between the pollutants and meteorological variables. In general, primary pollutants correlated strongly with each other and $\mathrm{PM}_{10}$ presented the highest correlations. $\mathrm{O}_{3}$ presented a negative correlation with $\mathrm{CO}$ but low and positive correlations with the other primary pollutants $(\mathrm{r} \leq$ $0.4)$. Humidity was correlated inversely with all pollutants, while, as expected, minimum temperature was negatively correlated with primary pollutants but not with $\mathrm{O}_{3}$.

Table 3 presents the estimated regression coefficients and standard errors of pollutants using single-pollutant models and one copollutant model with $\mathrm{PM}_{10}$ and $\mathrm{SO}_{2}$, those
Table 1. Descriptive data for the main variables used in the analysis.

\begin{tabular}{lcrr}
\hline & Daily mean $\pm \mathrm{SEM}$ & Minimum & Maximum \\
\hline Neonatal daily deaths & $6.11 \pm 0.08$ & 0 & 17 \\
Pollutants & & & \\
$\mathrm{NO}_{2}\left(\mu \mathrm{g} / \mathrm{m}^{3}\right)$ & $94.57 \pm 42.36$ & 23.52 & 308.91 \\
$\mathrm{SO}_{2}\left(\mu \mathrm{g} / \mathrm{m}^{3}\right)$ & $15.32 \pm 8.25$ & 2.26 & 71.47 \\
$\mathrm{CO}(\mathrm{ppm})$ & $2.83 \pm 1.38$ & 0.54 & 10.25 \\
$\mathrm{PM}_{10}\left(\mu \mathrm{g} / \mathrm{m}^{3}\right)$ & $48.62 \pm 21.18$ & 13.93 & 157.27 \\
$\mathrm{O}_{3}\left(\mu \mathrm{g} / \mathrm{m}^{3}\right)$ & $76.11 \pm 40.69$ & 11.88 & 280.48 \\
Weather variables & & & \\
Temperature ( $\left.{ }^{\circ} \mathrm{C}\right)$ & $15.10 \pm 3.53$ & -0.20 & 23.20 \\
Relative humidity (\%) & $80.30 \pm 8.70$ & 45.67 & 96.58
\end{tabular}

Number of days $=1096$

Table 2. Pairwise Pearson correlation coefficients between pollutants and meteorological variables.

\begin{tabular}{llllllll}
\hline & $\mathrm{CO}$ & $\mathrm{NO}_{2}$ & $\mathrm{SO}_{2}$ & $\mathrm{PM}_{10}$ & $\mathrm{O}_{3}$ & $\begin{array}{c}\text { Minimum Humidity } \\
\text { temperature }\end{array}$ \\
\hline $\mathrm{CO}$ & 1.00 & & & & & & \\
$\mathrm{NO}_{2}$ & $0.67^{*}$ & 1.00 & & & & & \\
$\mathrm{SO}_{2}$ & $0.55^{*}$ & $0.68^{*}$ & 1.00 & & & & \\
$\mathrm{PM}_{10}$ & $0.71^{*}$ & $0.76^{*}$ & $0.80^{*}$ & 1.00 & & & \\
$\mathrm{O}_{3}$ & -0.03 & $0.33^{*}$ & $0.29^{*}$ & $0.36^{*}$ & 1.00 & & \\
Minimum & $-0.10^{*}$ & $-0.09^{*}$ & -0.33 & $-0.23^{*}$ & 0.08 & 1.00 & \\
$\quad$ temperature & & & & & & & 0.00 \\
Humidity & -0.37 & -0.36 & -0.48 & -0.56 & -0.31 & 0.84 & 1.00 \\
\hline
\end{tabular}

${ }^{*} \mathrm{P}<0.05$.

Table 3. Estimated regression coefficients and standard errors for concurrent day pollutant concentrations using single-pollutant and co-pollutant models, and the index combining $\mathrm{PM}_{10}$ and $\mathrm{SO}_{2}$, controlling for seasonal trends, holidays, and weather variables.

\begin{tabular}{lccc}
\hline \multicolumn{3}{c}{ Coefficients and standard errors } \\
\cline { 2 - 4 } & Single-pollutant & $\begin{array}{c}\text { Co-pollutant } \\
\left(\mathrm{PM}_{10} \text { and } \mathrm{SO}_{2}\right)\end{array}$ & $\begin{array}{c}\text { Index }\left(\mathrm{PM}_{10} \text { and }\right. \\
\left.\mathrm{SO}_{2}\right)(\%)\end{array}$ \\
\hline $\mathrm{PM}_{10}$ & $0.0017(0.0008)$ & $0.0000(0.0011)$ & $0.1178(0.0036)$ \\
$\mathrm{SO}_{2}$ & $0.0063(0.0019)$ & $0.0063(0.0025)$ & - \\
$\mathrm{NO}_{2}$ & $0.0005(0.0003)$ & - & - \\
$\mathrm{CO}$ & $0.0061(0.0110)$ & - & - \\
$\mathrm{O}_{3}$ & $0.0004(0.0003)$ & - & -
\end{tabular}


which presented statistically significant associations with daily neonatal deaths in the single-pollutant models, and for the index created by us to represent both the effects of $\mathrm{PM}_{10}$ and $\mathrm{SO}_{2}$. The effects of $\mathrm{PM}_{10}$ and $\mathrm{SO}_{2}$ showed the best correlation coefficients when the concurrent day concentrations were used. Thus, we included in Table 3 the estimates of concurrent day levels for all pollutant terms analyzed. When both $\mathrm{PM}_{10}$ and $\mathrm{SO}_{2}$ were included simultaneously in the model, only $\mathrm{SO}_{2}$ remained significant. The index for $\mathrm{PM}_{10}$ and $\mathrm{SO}_{2}$ showed the strongest association with neonatal daily deaths.

The percent increases in daily neonatal deaths due to interquartile range increases in $\mathrm{PM}_{10}, \mathrm{SO}_{2}$, and index concurrent-day levels are presented in Figure 1. The acute effects attributed to usual variations in pollutant concentrations ranged from 4 to $6 \%$.

\section{Discussion}

The problem of air pollution and adverse outcomes in public health has been repeatedly investigated. Although the adverse effects of air pollution on public health have been consistently pointed out, several fields deserve additional investigation. Preterm birth and low birth weight associated with air pollution have been extensively studied (20-22) and both conditions may possibly lead to neonatal death. Thus, neonatal daily deaths associated with daily changes in pollutant levels are a subject worth exploring.

The present study reports adverse health

Figure 1. Increases in neonatal deaths due to interquartile range increases of $\mathrm{PM}_{10}\left(23.3 \mu \mathrm{g} / \mathrm{m}^{3}\right)$ and $\mathrm{SO}_{2}\left(9.2 \mu \mathrm{g} / \mathrm{m}^{3}\right)$ levels, and the $\mathrm{PM}_{10}$ and $\mathrm{SO}_{2}$ index $(0.52$ $\mu \mathrm{g} / \mathrm{m}^{3}$ ) on the concurrent day.

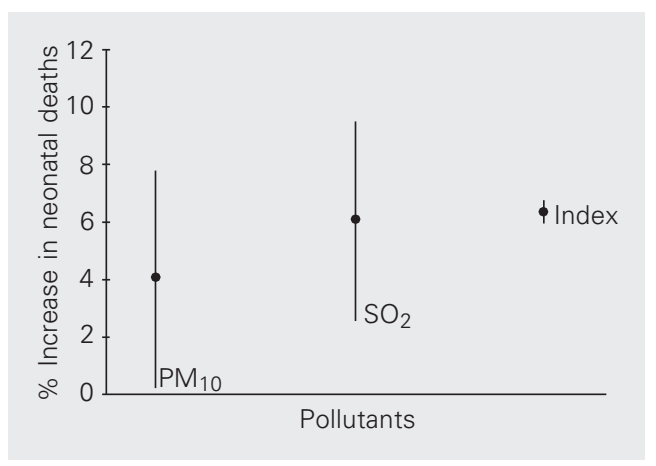

effects attributed to the exposure to the air pollutants such as increases in neonatal deaths that have not been explored before. In Brazil, neonatal deaths are events correlated with perinatal assistance more than with environmental factors (25). The associations reported in the present study were robust enough to resist modeling for the most usual confounding factors used in ecological timeseries studies of the adverse health effects of air pollution. Since the adopted endpoint is not usual, it is possible that some specific confounder may have been missed. Nevertheless, the lack or the poor quality of perinatal care are factors that cannot confound the association presented in this study because they do not show daily or even seasonal variations. Also, our results were estimated using $95 \%$ confidence intervals, which minimizes the possibility of the effects having occurred by chance. Two pollutants $\left(\mathrm{PM}_{10}\right.$ and $\mathrm{SO}_{2}$ ) were found to have consistent associations with daily neonatal deaths. Both pollutants were highly correlated with each other and have been associated with adverse respiratory health effects on children in our previous studies $(12,13,17)$.

Despite differences in age and outcomes, our study agrees with those by Braga et al. (17) and Bobak and Leon (26). Both showed associations between $\mathrm{PM}_{10}$ and $\mathrm{SO}_{2}$ with increased morbidity and mortality among infants.

The creation of an index containing both $\mathrm{PM}_{10}$ and $\mathrm{SO}_{2}$ allowed the observation of their cumulative effects on the daily death counts, a situation closer to the natural scenario. Associating highly correlated pollutants is a useful procedure that provides a better estimate of their effects and that has been applied elsewhere by us to estimate the compound effects of air pollutants in São Paulo (23).

The scenario of air pollution represents a particular situation in the metropolitan area of São Paulo. As occurs in Los Angeles, CA, USA, and in most of the large metropolitan 
regions of the world, the main source of air pollution in São Paulo is the fleet of almost $6,000,000$ vehicles. While fossil fuel is practically the only one used in the other cities, in São Paulo fuels of different origins are used, such as fossil, ethanol, a mixture of gasoline $(80 \%)$ and ethanol (20\%), and methane gas. The complex mixture of pollutants resulting from the combustion of different fuels may induce a unique and perhaps more severe susceptibility of certain population groups to air pollution, maximizing the adverse effects and permitting their better assessment.

In Brazil, PROCONVE, a national program, has been in effect since the mid-1980's to control air pollutant emissions from vehicles. Moreover, both the State Government and City Council of São Paulo have adopted other restrictive measures since 1995 in order to reduce the number of daily circulating automobiles. Together, these procedures have consistently and progressively reduced the levels of pollutants. The present study showed a consistent association between neonatal deaths and air pollution, indicating that current air pollution levels are still associated with the deleterious effects on public health. Although it is expected that population morbidity and mortality may improve when pollutant levels consistently fall, for neonates, more sensitive than adults to the effects of air pollution, the desired levels of air contamination have not yet been reached. It is clear that more consistent restrictive measures against air pollution should be adopted.

The short time lag between the increases in pollutant levels and the increases in neonatal deaths suggests that the effects of the pollutants were consistent and directly influenced neonatal deaths. We do not have enough information to conduct an analysis of cause-specific neonatal deaths. Probably most of them are due to respiratory problems, explaining the acute effects.

This study contributed to the epidemiological investigation of the effects of air pollution on children's health, expanding susceptible age groups and outcomes and showed that the size of air pollution-associated disease burden is still unknown.

\section{References}

1. Committee of the Environmental and Occupational Health of the American Thoracic Society (1996). Health effects of outdoor air pollution. American Journal of Respiratory and Critical Care Medicine, 153: 3-50.

2. Dockery DW, Pope III CA, Xu X, Spengler JD, Ware JH, Fay ME, Ferris Jr BG \& Speizer FE (1993). An association between air pollution and mortality in six US cities. New England Journal of Medicine, 329: 1753-1759.

3. Dockery DW \& Pope III CA (1994). Acute respiratory effects of particulate air pollution. Annual Review of Public Health, 15: 107132.

4. Peters A, Goldstein IF, Beyer U, Franke K, Henrich J, Dockery DW, Spengler JD \& Wichmann HE (1996). Acute health effects of high levels of air pollution in Eastern Europe. American Journal of Epidemiology, 144: 570-581.

5. Saldiva PHN, Pope III CA, Schwartz J, Dockery DW, Lichtenfels AJ, Salge JM, Barone I \& Böhm GM (1995). Air pollution and mortality in elderly people: a time-series study in São Paulo, Brazil. Archives of Environmental Health, 50: 159-163.

6. Schwartz $J$ (1994). Air pollution and daily mortality: a review and meta analysis. Environmental Research, 64: 36-52.

7. Spengler JD, Koutrakis P, Dockery DW, Raizenne M \& Speizer FE
(1996). Health effects of acid aerosols on North American children: air pollution exposures. Environmental Health Perspectives, 104: 492-499.

8. Schwartz J, Dockery DW, Neas LM, Wy PIJD, Ware JH, Spengler JD, Koutrakis P, Speizer FE \& Ferris Jr BG (1994). Acute effects of summer air pollution on respiratory symptom reporting in children. American Journal of Respiratory and Critical Care Medicine, 150: 1234-1242

9. Dockery DW, Cunnighan J, Damokosh Al, Neas LM, Spengler JD, Koutrakis P, Ware JH, Raizenne M \& Speizer FE (1996). Health effects of acid aerosols on North American children: respiratory symptoms. Environmental Health Perspectives, 104: 500-505.

10. Hoppenbrouwers $T$ (1990). Airways and air pollution in childhood: state of the art. Lung, 168 (Suppl): 335-346.

11. Pope III CA \& Dockery DW (1992). Acute health effects of $\mathrm{PM}_{10}$ pollution on symptomatic and asymptomatic children. American Review of Respiratory Disease, 145: 1123-1128.

12. Braga ALF, Conceição GMS, Pereira LAA, Kishi H, Pereira JCR, Andrade MF, Gonçalves FLT, Saldiva PHN \& Latorre MRDO (1999). Air pollution and pediatric respiratory admissions in São Paulo, Brazil. Journal of Environmental Medicine, 1: 95-102.

13. Lin CA, Martins MA, Farhat SCL et al. (1999). Air pollution and 
respiratory illness of children in São Paulo, Brazil. Paediatric and Perinatal Epidemiology, 13: 475-488.

14. Loomis D, Castillejos M, Gold DR, McDonnel W \& Borja-Aburto VH (1999). Air pollution and infant mortality in Mexico City. Epidemiology, 10: 118-123

15. Saldiva PHN, Lichtenfels AJFC, Paiva PSO, Barone IA, Martins MA, Massad E, Pereira JCR, Xavier VP, Singer JM \& Böhm GM (1994). Association between air pollution and mortality due to respiratory diseases in children in São Paulo, Brazil: a preliminary report. Environmental Research, 65: 218-225.

16. Conceição GMS, Miraglia SGEK, Kishi HS, Saldiva PHN \& Singer JM (2001). Air pollution and child mortality: A time-series study in São Paulo, Brazil. Environmental Health Perspectives, 109 (Suppl 3): 347-350.

17. Braga ALF, Saldiva PHN, Pereira LAA, Menezes JJC, Conceição GMS, Lin CA, Zanobetti A, Schwartz J \& Dockery DW (2001). Health effects of air pollution exposure on children and adolescents in São Paulo, Brazil. Pediatric Pulmonology, 31: 106-113.

18. Woodruff TJ, Grillo J \& Schoendorf KC (1997). The relationship between selected causes of postneonatal infant mortality and particulate air pollution in the United States. Environmental Health Perspectives, 105: 608-612.

19. Ritz B, Fruin S, Chapa G, Shaw GM \& Harris JA (2002). Ambient air pollution and risk of birth defects in Southern California. American
Journal of Epidemiology, 155: 17-25.

20. Ritz B, Chapa G \& Fruin S (2000). Effect of air pollution on preterm birth among children born in Southern California between 1989 and 1993. Epidemiology, 11: 502-511.

21. Wang $X$, Ding $H$, Ryan $L \& X u X$ (1997). Association between air pollution and low birth weight: a community-based study. Environmental Health Perspectives, 105: 514-520.

22. Bobak L \& Leon DA (1999). Pregnancy outcomes and outdoor air pollution: an ecological study in districts of the Czech Republic 1986-1988. Occupational and Environmental Medicine, 56: 539543.

23. Pereira LAA, Loomis D, Conceição GMS, Braga ALF, Arcas RM, Kishi H, Singer JM, Böhm GM \& Saldiva PHN (1998). Association between air pollution and intrauterine mortality in São Paulo, Brazil. Environmental Health Perspectives, 106: 325-329.

24. CETESB (1999). Relatório de Qualidade do Ar no Estado de São Paulo - 1998. CETESB, São Paulo, SP, Brazil.

25. Vermelho LL, Costa AJL \& Cale PL (2003). Indicadores de Saúde. In: Medronho AR (Editor), Epidemiologia. Editora Ateneu, São Paulo, SP, Brazil, 33-55.

26. Bobak M \& Leon DA (1999). The effect of air pollution on infant mortality appears specific for respiratory causes in the postneonatal period. Epidemiology, 10: 666-670. 